\title{
INCIDÊNCIA DE RINOTRAQUEÍTE INFECCIOSA BOVINA (IBR), DIARREIA VIRAL BOVINA (BVD) E LEPTOSPIROSE EM BOVINOS LEITEIROS DA REGIÃO OESTE DE SANTA CATARINA - BRASIL
}

\author{
Willian Pasqualotto* \\ Simone Sehnem** \\ Cesar Augustus Winck***
}

RESUMO: Neste trabalho, buscou-se verificar a incidência de IBR, BVD e Leptospirose em 195 propriedades localizadas no Oeste catarinense. Após a coleta, as amostras de soro (842 amostras) foram enviadas ao Setor de Virologia da Universidade Federal de Santa Maria (UFSM) e da Universidade Estadual Paulista (UNESP), responsáveis pela análise das amostras. Verificou-se que $\mathbf{5 7 , 5 4 \%}$ das amostras de soro foram positivas para IBR, 28,5\% positivas para BVD e 31,67\% positivas para Leptospirose. As principais constatações do estudo foi a detecção de sorologia positiva para ambas as doenças mesmo em rebanhos bovinos onde a incidência de problemas reprodutivos foi baixa ou inexistente, sugerindo que a ocorrência ou não dos sinais clínicos característicos das infecções estejam relacionados com as técnicas gerais de manejo adotadas em cada propriedade. Portanto, conclui-se que estas doenças estão disseminadas nos rebanhos leiteiros do Oeste catarinense, necessitando em caráter de urgência da implantação de práticas de manejo, como controle na aquisição e introdução de novos animais, cuidados na inseminação artificial, realização periódica de exames, adoção de calendários de vacinações eficientes e controle de roedores e animais silvestres, para que se obtenha o máximo da eficiência reprodutiva do rebanho.

PALAVRAS-CHAVE: Atividade Leiteira; Diarreia Viral Bovina (BVD); Leptospirose; Reprodução; Rinotraqueíte Infecciosa Bovina (IBR).

\footnotetext{
"Discente do Curso de Pós-Graduação, em nível de Especialização, em Gestão, Manejo e Nutrição na Bovinocultura Leiteira, UNOESC - São Miguel do Oeste (SC), Santa Catarina, Brasil.

** Doutorado em Administração e Turismo pela UNIVALI; Docente Permanente do Mestrado Profissional em Administração da UNOESC e Docente Colaboradora do Mestrado Acadêmico de Administração da UNISUL, Departamento de Administração, Chapecó (SC), Brasil; E-mail: simonesehnem_adm@yahoo.com.br

*** Doutorado em Agronegócios pela UFRGS; Docente Permanente do Mestrado Profissional em Administração da UNOESC, Departamento de Administração, Chapecó (SC), Brasil.
} 


\section{OCCURRENCE OF INFECTIOUS BOVINE RHINOTRACHEITIS (IBR), BOVINE VIRAL DIARRHEA (BVD) AND LEPTOSPIROSIS (LEP) IN DAIRY CATTLE IN THE WESTERN REGION OF THE STATE OF SANTA CATARINA, BRASIL}

ABSTRACT: The occurrence of IBR, BVD and LEP on 195 farms in the western region of the state of Santa Catarina, Brazil, is discussed. Serum samples (842 samples) were analyzed by the Virology Sector of the Universidade Federal de Santa Maria (UFSM) and of the Universidade Estadual Paulista (UNESP). Results showed that $57.54 \%$ of serum samples were positive for IBR; $28.5 \%$ were positive for BVD and $31.67 \%$ were positive for LEP. The study detected positive serology for the two diseases even in herds where the occurrence of reproductive problems was low or non-existent. The above suggested that the occurrence or not of the characteristic clinical signs of infection are related to the general management techniques on each farm. Results show that the above-mentioned diseases are disseminated in cattle herds in the western region of Santa Catarina and require the urgent implantation of management practices such as control during acquisition and admittance of new animals, care in artificial insemination, periodical tests, adoption of efficient vaccines timetables and control of rodents and wild animals so that maximum reproductive efficiency of the herd could be achieved.

KEY WORDS: Dairy Activity; Bovine Viral Diarrhea (BVD); Leptospirosis; Reproduction; Infectious Bovine Rhinotracheitis (IBR).

\section{INTRODUÇÃO}

A viabilidade econômica da produção leiteira é decisiva para a manutenção e o crescimento dos produtores dentro da atividade. Esta viabilidade é o resultado de inúmeros fatores, que em grande parte dependem do controle e manejo a que o produtor submete seu rebanho. Dentre estes, a eficiência reprodutiva é um dos determinantes para o sucesso da atividade que depende da produção de animais saudáveis e potencialmente produtivos. A atividade leiteira na região Oeste catarinense caracteriza-se pelo predomínio de pequenas propriedades rurais de mão de obra familiar, onde a produção de leite divide espaço com outras atividades como a suinocultura, a avicultura, plantações de milho e a fumicultura. 
A realização e execução de programas de saúde animal, que incluem protocolos de vacinação, ficam a cargo do produtor, que acaba não contratando um profissional especializado para realizar o acompanhamento sanitário do rebanho. Frequentemente, os indícios da presença de doenças infectocontagiosas nestas propriedades passam despercebidos e o diagnóstico efetivo só acontece quando os patógenos já se disseminaram entre o rebanho e os prejuízos econômicos são consideráveis. Sendo assim, a produção de leite, principal fonte de renda da pecuária leiteira, está vinculada à parição, tendo-se como objetivo primordial alcançar a máxima produção de leite por dia de vida da vaca, a um mínimo custo alimentar. Para isso, pressupõe-se que as vacas devem parir em intervalos regulares, devendo, portanto, serem inseminadas e tornarem-se gestantes dentro de um período restrito de tempo. Caso a concepção seja atrasada, a ineficiência reprodutiva pode levar à ineficiência na produção de leite, comprometendo economicamente a atividade.

O bom desempenho reprodutivo de um rebanho constitui em um dos principais fatores para o sucesso na bovinocultura. Contudo, são muitas as condições que interferem na eficiência reprodutiva dos bovinos, destacando-se entre as mesmas nos rebanhos do Brasil as causas de ordem alimentar e infecciosa. Diante disso, este estudo foi norteado pelo aspecto de apurar o índice de ocorrência dos agentes infecciosos causadores das doenças IBR, BVD e Leptospirose em animais com problemas reprodutivos, em rebanhos leiteiros da região Oeste catarinense. As perdas reprodutivas podem, muito frequentemente, estar relacionadas à incidência de doenças infectocontagiosas, dentre elas a Rinotraqueíte Infecciosa Bovina (IBR), Diarreia Viral Bovina (BVD) e a Leptospirose, que se instalam no rebanho e se espalham de maneira silenciosa, causando infertilidade, mortes embrionárias, abortos e defeitos congênitos. A IBR é uma infecção conhecida principalmente como enfermidade do trato respiratório e reprodutivo; síndromes como conjuntivite, balanopostite e vulvovaginite também podem ser observadas. A BVD é considerada um dos patógenos de bovinos mais comuns em todo o mundo e está associada a múltiplas manifestações clínicas, incluindo diarreia aguda, doença das mucosas, diarreia crônica e problemas reprodutivos (PEREIRA et al., 2009). A Leptospirose é uma zoonose, de alta incidência, que traz redução na eficiência reprodutiva e produtiva, além de perdas na qualidade dos produtos (PIVETTA, 2009). 
Os causadores destas doenças encontram-se amplamente distribuídos pelo Brasil com altos índices de infecção. Inquéritos sorológicos realizados em todo o país têm demonstrado altos percentuais de soro-conversão de fêmeas bovinas para o Herpesvírus Bovino 1 (BHV-1), agente causador da IBR, para o Vírus da Diarreia Viral Bovina (BVD) e para a Leptospirose (MENDES et al., 2009). Del Fava et al. (2003) relatam uma prevalência entre $60 \%$ e $90 \%$ de animais portadores de anticorpos para BVD nos rebanhos mundiais e citam trabalhos que apontam a presença de $60,4 \%$ de animais soro reagentes à Leptospirose em 56 propriedades analisadas em seis estados brasileiros. No Estado do Paraná, estudos apontaram um índice de 41,9\% de animais e $90,5 \%$ dos rebanhos positivos para o vírus causador da Diarreia Viral Bovina (DIAS et al., 2008).

Portanto, justifica-se a elaboração deste estudo pois o mesmo procura identificar alternativas para reduzir a incidência e as perdas reprodutivas e econômicas ocasionadas por doenças relacionadas à reprodução do rebanho e permitir que empresas agropecuárias, técnicos e demais profissionais envolvidos na cadeia produtiva do leite, possam ampliar e direcionar seus trabalhos no que tange à incidência $\mathrm{e}$ controle de doenças infectocontagiosas reprodutivas na região. Outrossim, a consulta a bases de dados científicas (SCIELO, EBSCO E PROQUEST) não identificou publicações que se referem ao índice de diagnóstico em propriedades do Oeste de Santa Catarina. Além disso, evidencia-se um diagnóstico da situação epidemiológica destas doenças nas pequenas propriedades rurais, o que contribuirá com o melhor desempenho econômico do produtor através da otimização de práticas de manejo adequadas às suas necessidades.

$O$ presente estudo teve como objetivo principal diagnosticar a incidência de IBR, BVD e Leptospirose em animais que apresentam sintomas reprodutivos em rebanhos de bovinos leiteiros de pequenas propriedades rurais da região Oeste do Estado de Santa Catarina e que interferem na eficiência reprodutiva. Os objetivos específicos consistiram em: a) relacionar os resultados de amostras de sangue previamente coletadas; b) analisar os resultados obtidos nas coletas em animais com possíveis problemas reprodutivos de pequenas propriedades rurais da região Oeste catarinense; c) avaliar qual é a que tem maior ocorrência entre estas doenças; d) destacar quais são as principais perdas reprodutivas e econômicas; e, e) identificar alternativas para reduzir a incidência das doenças reprodutivas citadas. 


\title{
2 MANEJO PREVENTIVO
}

O controle das doenças anteriormente descritas, bem como de outras enfermidades que atingem os rebanhos bovinos, envolve além de práticas de manejo adequadas e fornecimento de uma condição nutricional que atenda às exigências dos animais, o controle na aquisição e introdução de novos animais na propriedade, cuidados na inseminação artificial e qualidade do sêmen utilizado, cuidados higiênico-sanitários, sorodiagnóstico periódico dos animais do plantel e reprodutores e, principalmente, a adoção de calendários de vacinação, que devem ser seguidos corretamente e efetuados de acordo com a orientação de um técnico, assim como a eliminação do rebanho daqueles animais considerados problema, que servem como fonte constante de eliminação do agente causador no ambiente.

Segundo Halfen e Vidor (2001), o uso de vacinas contra BHV-1 e BHV-5 não impede a infecção pelo vírus, mas reduz consideravelmente a incidência da doença, minimizando seu curso e a manifestação dos sintomas clínicos, controlando a ocorrência de surtos e diminuindo as perdas econômicas decorrentes da ação do vírus. Schuch (2001) indica que o uso de esquemas de vacinação atua diretamente no controle da BVD, reduzindo o efeito supressor do vírus que favorece a instalação de infecções respiratórias. Usualmente, as vacinas disponíveis hoje no mercado são formuladas com vários antígenos (IBR, BDV, Leptospirose, Parainfluenza tipo 3 , vírus Respiratório Sincicial Bovino) e classificam-se em duas categorias: as vacinas desenvolvidas com vírus vivo modificado e as vacinas com o vírus inativado.

\begin{abstract}
As vacinas com vírus vivo modificado induzem uma rápida e duradoura resposta imunológica, entretanto, como a cepa vacinal é capaz de replicar-se no hospedeiro, há liberação de vírus vacinal, estabelecimento de infecção latente e podem ocorrer abortos, devendo-se ter prudência no seu uso. Por outro lado, as vacinas inativadas [...] são seguras quanto ao uso, mas são necessárias várias doses e adição de adjuvantes vacinais, para manter-se um nível adequado de imunidade (HALFEN; VIDOR, 2001).
\end{abstract}

Não existe hoje um programa elaborado pelos Órgãos de Defesa Animal para o controle das infecções reprodutivas, ficando a critério dos profissionais da área e de produtores a adoção de medidas preventivas, mas de maneira geral, o esquema de vacinação utilizando-se vacinas inativadas propõe a aplicação da primeira 
dose da vacina em bezerros no segundo mês de vida, com reforço de 21 a 28 dias após e revacinação anual, com uma aplicação no intervalo de seis meses de vacina contra Leptospirose. Segundo Halfen e Vidor (2001), para prevenir a forma reprodutiva, as fêmeas devem ser vacinadas com duas doses antes do serviço com um intervalo de quatro semanas.

Portanto, a incidência de doenças infecciosas em rebanhos bovinos afeta diretamente a produtividade dos mesmos. Conhecer tais doenças e fazer um diagnóstico do rebanho do extremo oeste catarinense pode significar o primeiro passo para a elaboração e proposição de um plano de contingenciamento e de alternativas para mitigar as doenças Diarreia Viral Bovina (BVD), Rinotraqueíte Infecciosa Bovina (IBR) e Leptospirose, no Oeste de Santa Catarina. Na sequência, a seção 3 descreve o caminho percorrido para desenvolver a pesquisa, bem como o enquadramento metodológico da mesma.

\section{MATERIAL E MÉTODOS}

Este estudo possui como propósito identificar a incidência de IBR, BVD e Leptospirose, doenças que interferem na eficiência reprodutiva de bovinos de leite a partir de pesquisa bibliográfica e pesquisa de campo. Os dados da pesquisa de campo foram coletados entre os anos de 2011 e 2012, e obtidos em 195 propriedades rurais, localizadas em 45 municípios da região Oeste de Santa Catarina, que tem na produção leiteira uma das principais fontes de renda. Nestas propriedades foram coletadas 842 amostras de sangue de animais em idade reprodutiva e com histórico de problemas reprodutivos, como aborto e mortalidade embrionária precoce. Estas amostras foram coletadas para análise de Leptospirose, IBR e BVD. O estudo foi conduzido por uma empresa que comercializa medicamentos para a bovinocultura.

A pesquisa bibliográfica caracterizou-se pela análise de livros, artigos científicos, periódicos, boletins informativos, publicações em sites da área nos quais foram extraídos e analisados os fundamentos e outros estudos realizados. Para Gil (2007, p. 65) "a pesquisa bibliográfica permite ao investigador a cobertura de uma gama de fenômenos muito mais ampla do que aquela que poderia pesquisar diretamente". 
A pesquisa de campo foi desenvolvida por dois médicos veterinários que prestam assistência técnica aos produtores rurais e baseou-se na aplicação de questionários não-estruturados, resgate de dados produtivos e coleta de amostras de sangue. Para Gil (2007, p. 72) "o planejamento do estudo de campo apresenta maior flexibilidade, ocorrendo mesmo que seus objetivos sejam reformulados durante $o$ processo de desenvolvimento da pesquisa".

O critério de seleção de propriedades e animais para coleta de sangue foi baseado em uma amostragem não probabilística por tipicidade ou intencional, visto que ocorria conforme a solicitação dos produtores, sendo que o número de amostras coletadas em cada propriedade era influenciado por variáveis como tamanho de cada rebanho, número de animais em repetição de cio, mortalidade embrionária precoce e tardia, abortos em qualquer fase de gestação, ou mesmo coletas realizadas em propriedades que não apresentavam animais com sintomas clínicos das doenças. Os rebanhos bovinos que foram avaliados eram constituídos de animais leiteiros da raça Holandesa, Jersey e mestiços entre as raças. As coletas de sangue ocorreram através de punção venosa, sendo as amostras acondicionadas em frascos específicos estéreis para coleta com volume total de $10 \mathrm{ml}$ devidamente identificados. O sangue era mantido em temperatura ambiente até a retração do coágulo para a obtenção do soro e após aliquotado em novos frascos estéreis devidamente identificados e armazenados a $-20^{\circ} \mathrm{C}$ em freezer até o envio para o laboratório.

Após a coleta, as amostras de soro eram enviadas ao Setor de Virologia do Laboratório da Universidade Federal de Santa Maria e da Universidade Estadual Paulista (UNESP), responsáveis pela análise das amostras. Os testes efetuados no laboratório buscavam a detecção dos soros positivos para Diarreia Viral Bovina e Rinotraqueíte Infecciosa Bovina empregando a técnica de Neutralização Viral (Virusneutralização), conforme recomendação da Organização Internacional de Epizootias (OIE). Para o diagnóstico da Leptospirose empregou-se a técnica de Soroaglutinação Microscópica (SAM) com antígenos vivos, segundo o Manual de Leptospirose do Ministério da Saúde (1995), a fim de buscar a titulação de anticorpos contra Leptospirose.

Para operacionalizar este estudo foi elaborado o Quadro 1, que evidencia quais foram as fontes de coleta de dados da pesquisa, aspectos abordados, sistematização da informação e as bases constitutivas para análise. 


\begin{tabular}{|c|c|c|c|c|c|}
\hline 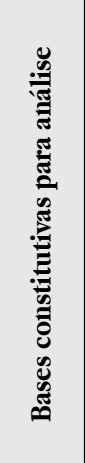 & 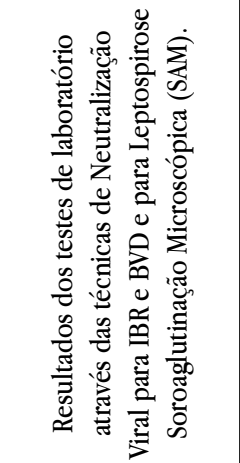 & 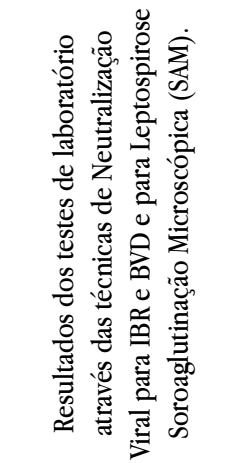 & 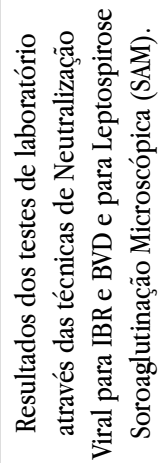 & 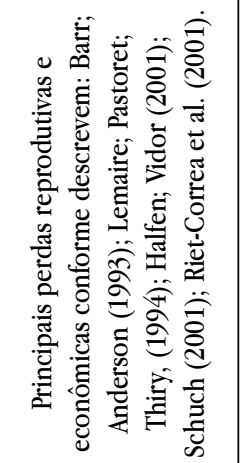 & 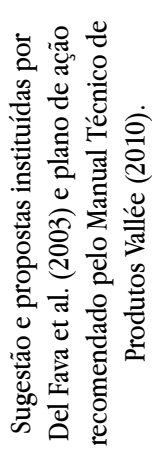 \\
\hline 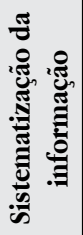 & 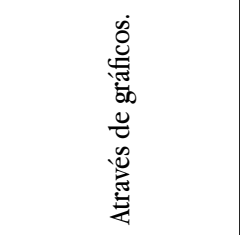 & 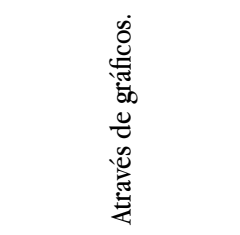 & 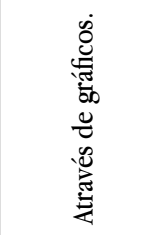 & 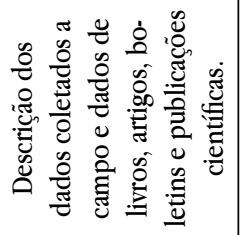 & 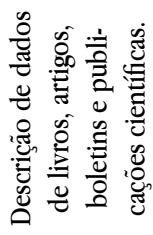 \\
\hline 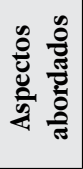 & 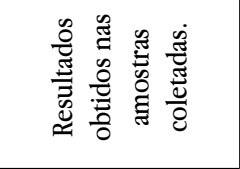 & 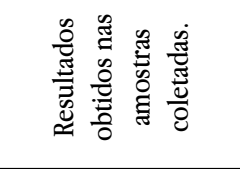 & 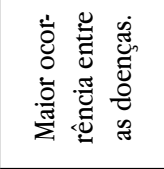 & 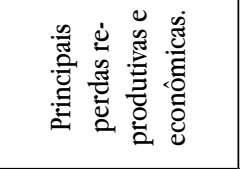 & 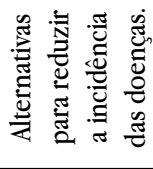 \\
\hline 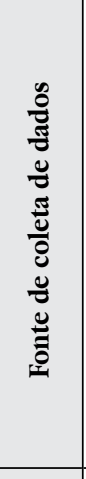 & 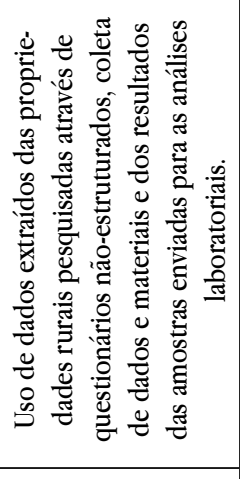 & 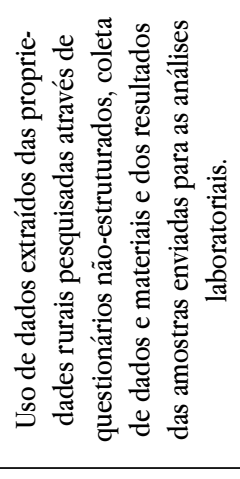 & 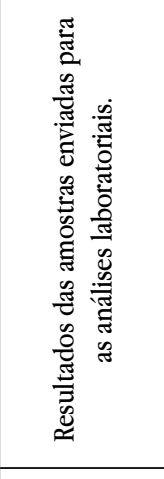 & 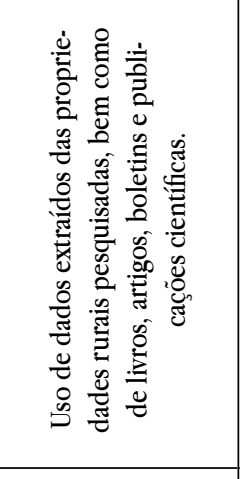 & 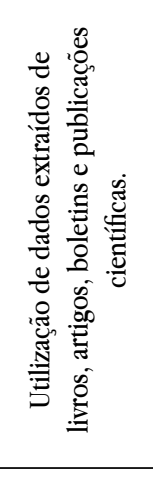 \\
\hline 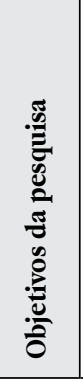 & 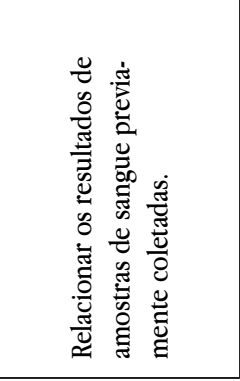 & 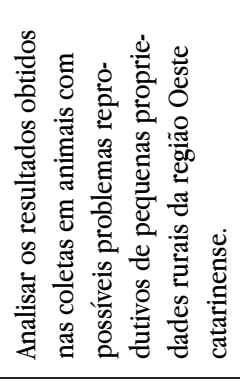 & 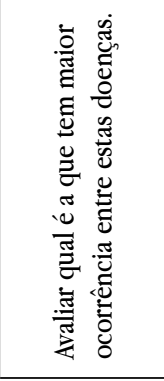 & 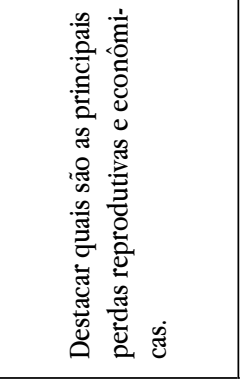 & 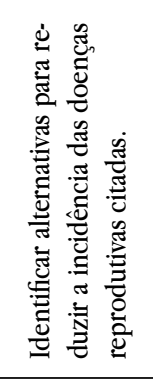 \\
\hline
\end{tabular}


Portanto, ficou evidenciado no Quadro 1 de que somente foram buscados dados junto às propriedades rurais pesquisadas. Foram descritos os resultados das amostras enviadas ao laboratório e informações secundárias obtidas por meio da consulta a livros, artigos, boletins e publicações científicas para fins de coleta de dados teóricos. Os resultados são apresentados em percentuais, onde os dados e informações são sistematizados por meio de gráficos, tabelas, análises, sugestões. Assim, fez-se uso da estatística descritiva simples.

\section{RESULTADOS E DISCUSSÃO}

Os estudos sobre a incidência de doenças reprodutivas na região Oeste de Santa Catarina são bastante limitados, não sendo encontradas até o momento, publicações que retratem percentuais de ocorrência nesta região e possibilitem um comparativo com os dados encontrados neste estudo.

Os resultados obtidos são descritos em quatro etapas, sendo três referentes às incidências individuais de cada doença e uma quarta etapa analisando qual teve maior ocorrência de casos entre essas doenças. Os resultados obtidos através das coletas realizadas demonstram um alto número de animais positivos para Leptospirose, IBR e BVD.

Identificou-se alta incidência de agentes causadores de doenças reprodutivas infecto-contagiosas nas propriedades da região. Além disso, é importante levar em consideração as características de cada agente como, por exemplo, o BHV-1, causador da IBR, que tem a capacidade de estabelecer latência o que garante a manutenção e mesmo a expansão da infecção no rebanho. A partir disso, percebe-se que a presença de alguns animais portadores do vírus indica que há uma grande incidência deste agente, mesmo que sem a manifestação de sintomas clínicos.

Segundo Lemaire, Pastoret e Thiry (1994), uma vez sofrida infecção primária, $\mathrm{o}$ animal se torna portador do BHV-1 por toda sua vida, potencialmente atuando como fonte de infecção para indivíduos susceptíveis, assegurando a permanência da infecção no plantel. O impacto econômico desta enfermidade é observado pelo retardo do crescimento de animais jovens, menor produção leiteira, morte embrionária e fetal, abortamento com maior frequência no segundo e terceiro trimestres 
de gestação (BARR; ANDERSON, 1993), reduzida eficiência reprodutiva de matrizes e touros (LEMAIRE; PASTORET; THIRY, 1994), além das restrições ao comércio internacional de animais vivos e seus produtos como sêmen, embriões e produtos de biotecnologia.

\section{INCIDÊNCIA DE RINOTRAQUEÍTE INFECCIOSA BOVINA}
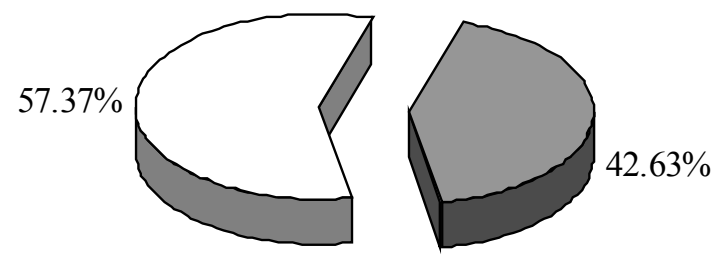

POSITIVAS

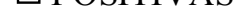

$\square$ NEGATIVAS

Gráfico 1. Incidência de IBR em 842 amostras das propriedades da região Oeste de Santa Catarina. Fonte: Elaborado pelos autores (2013).

Conforme o Gráfico 1, do total de amostras analisadas neste estudo, 57,54\% (482/842) foram positivas para o agente BHV-1. O resultado da pesquisa de campo é semelhante a um estudo citado por Dias et al. (2008), que foi realizado no Estado do Paraná em propriedades com histórico de problemas reprodutivos, onde verificouse uma incidência de $41,9 \%$ animais e $90,5 \%$ dos rebanhos positivos ao vírus.

A Tabela 1 mostra um crescente número de casos de IBR na região Sul do Brasil. No Estado do Rio Grande do Sul, no ano de 1988 foi relatada uma incidência de 22\% da doença, já no ano de 1993 um estudo que envolvia também o Estado de Santa Catarina identificou uma ocorrência de 43\%, e no ano de 1995 outro estudo atingiu $71 \%$. Vidor et al. (1995) avaliaram amostras provenientes de 112 propriedades dos estados do Sul do Brasil, São Paulo, Argentina e Uruguai, encontrando um percentual de amostras positivas de $71,3 \%$, porém, de 32 amostras coletadas no município de Concórdia (pertencente à região Oeste catarinense) nenhuma de- 
las apresentou sorologia positiva para IBR, o que difere dos resultados obtidos nas amostras provenientes da região Oeste do Estado.

Tabela 1. Ocorrência de IBR no Brasil nos últimos anos

\begin{tabular}{l|c|c|c}
\hline Região & Ano & Autor & Ocorrência \\
\hline SP & 1981 & Mueller & $42 \%$ \\
BA & 1982 & Ribeiro & $74 \%$ \\
MG, PR, RS, SP & 1988 & Pituco & $22 \%$ \\
MG & 1992 & Castro & $51 \%$ \\
PR & 1992 & Kruger & $11 \%$ \\
MG, PR, RS, SP, DF, BA, MS, MT, RJ, SC & 1993 & Pituco & $43 \%$ \\
RS & 1995 & Vidor & $71 \%$ \\
SP, MG, MS, PR, RJ, RS & 1996 & Richtzenhain & $68,70 \%$ \\
\hline
\end{tabular}

Fonte: Adaptado de Dias et al. (2008).

Referente à Diarreia Viral Bovina (BVD) sabe-se que a mesma está relacionada a perdas de ordem produtiva e reprodutiva, que incluem diminuição na produção de leite, aumento nas taxas de retorno ao cio, abortos, nascimento de animais fracos, entre outras. Alguns trabalhos citam a BVD como uma doença endêmica dos rebanhos principalmente devido às altas taxas de soroprevalência que são encontradas em todas as regiões do país. Pereira et al. (2009) citam trabalhos de Flores et al. (2005) em que foram encontradas taxas de 40 a $80 \%$ de animais positivos em diversos estados brasileiros. Neste estudo os índices nos Estados do Paraná e Rio Grande do Sul chegaram respectivamente a $67 \%$ e $73 \%$.

No Rio Grande do Sul, Krahl et al. (1997) pesquisaram anticorpos para BVD em 1.823 soros bovinos pela técnica de soroneutralização, encontrando $23,4 \%$ de amostras soropositivas, sendo que, das 265 propriedades examinadas, $171(64,53 \%)$ apresentaram animais reagentes.

Richtzeinhain (1999) analisou pela técnica de soroneutralização 2.448 amostras provenientes de 56 propriedades em diversos estados do país, e encontrou a prevalência de 65\% em Minas Gerais, 84\% no Mato Grosso do Sul, 67\% no Paraná, 71\% no Rio de Janeiro, 73\% no Rio Grande do Sul e 78\% em São Paulo, sendo que em todas as fazendas havia pelo menos um animal soropositivo. Entre as amostras 
avaliadas neste estudo se encontra um percentual de ocorrência abaixo dos estudos citados anteriormente; conforme mostra o Gráfico 2, a incidência de BVD foi de $28,5 \%(240 / 842)$.

De acordo com os resultados das pesquisas relatadas anteriormente por diversos autores, e também dos resultados obtidos na atual pesquisa de $28,5 \%$ das amostras positivas, é possível comprovar uma disseminação muito grande da doença entre os animais e os rebanhos. Este índice desperta preocupação epidemiológica principalmente pela possível presença de animais persistentemente infectados (PI) nesses rebanhos, pois quando o animal PI não for identificado este se torna um grave problema na propriedade, pois excretam uma enorme quantidade de vírus, aumentando o nível de infecção no rebanho, infectando assim todos os animais soronegativos.

\section{INCIDÊNCIA DE DIARRÉIA VIRAL BOVINA}

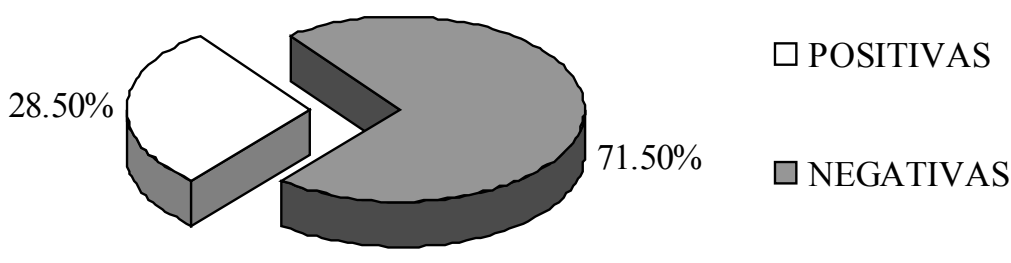

Gráfico 2. Incidência de BVD em 842 amostras das propriedades da região Oeste de Santa Catarina. Fonte: Elaborado pelos autores (2013).

Outra doença reprodutiva de distribuição mundial e que impacta economicamente a produção leiteira é a Leptospirose. Além dos prejuízos econômicos, causa também prejuízos à saúde pública, visto que é uma zoonose. Sua disseminação é feita pelos roedores que são portadores naturais da bactéria ou, via urina, placenta, descargas cérvico-vaginais, fetos abortados e sêmen de bovinos portadores em fase 
reprodutiva. Dias et al. (2008) aponta que de 2.761 amostras coletadas pelo período de um ano em todo o Estado de São Paulo, 45,56\% destas foram positivas para a presença de Leptospira. Castro et al. (2008) avaliaram 8.216 amostras sorológicas de fêmeas bovinas em idade reprodutiva, também coletadas em todo o Estado de São Paulo e foi obtida uma soroprevalência de 49,4\%, sendo que o sorovar de maior prevalência foi o Hardjo, encontrado em $46,0 \%$ das amostras. Os resultados encontrados pelos autores, conforme a Tabela 2, são semelhantes aos diagnosticados nas amostras coletadas neste trabalho.

Tabela 2. Incidência de Leptospirose encontrada em pesquisas nacionais.

\begin{tabular}{l|l|l|c|c}
\hline Região & Ano & Autor & Amostras & Ocorrência \\
\hline MG & 1979 & Moreira et al. & 2.702 & $27,83 \%$ \\
MS & 1980 & Madruga et al. & 670 & $74,50 \%$ \\
Porto Alegre & 1985 & Abuchaim et al. & 1.000 & $49,80 \%$ \\
Estados da região Sul, Sudeste e & 1997 & Vasconcelos apud & 2.448 & $61 \%$ \\
\hline
\end{tabular}

Fonte: Adaptado de Dias et al. (2008).

$\mathrm{Na}$ pesquisa realizada na região Oeste catarinense identificou-se uma incidência de 31,67\% (229/723) amostras positivas para Leptospira spp, em 723 amostras de sangue coletadas em 2011 e 2012, conforme o Gráfico 3 . O número de amostras para Leptospirose foi menor do que para IBR e BVD, pois algumas amostras foram rejeitadas durante a análise laboratorial em virtude de hemólise e toxicidade nas amostras. É importante destacar que muitos animais apresentaram reações múltiplas a dois ou mais antígenos ou sorovar testados para Leptospirose, portanto não serão apresentados neste trabalho. 


\section{INCIDÊNCIA DE LEPTOSPIROSE}

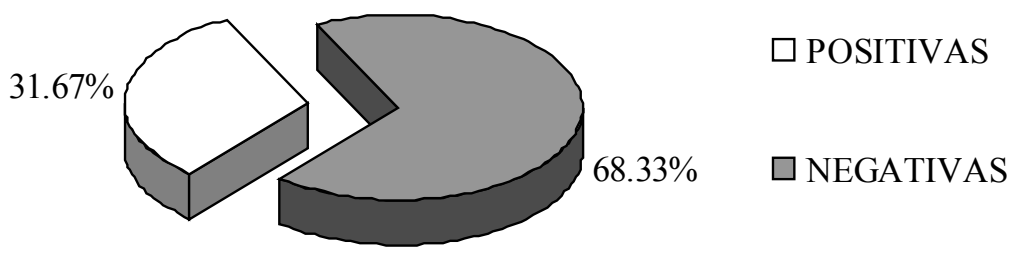

Gráfico 3. Incidência de Leptospirose em 723 amostras das propriedades da região Oeste de Santa Catarina.

Fonte: Elaborado pelos autores (2013).

A detecção de 229 animais reagentes nas amostras sorológicas coletadas em propriedade da região Oeste de Santa Catarina indica a presença de Leptospira spp. em grande parte do território estudado. No Brasil, estudos sorológicos realizados em animais de produção também demonstraram que a infecção por este microorganismo está bastante difundida. Frente a estas colocações, o alastramento desta doença entre os rebanhos sugere provavelmente a influência de alguns fatores como a densidade bovina, condições ambientais e climáticas, tipo de solo, sistema de criação, a criação simultânea de animais de diversas espécies, a presença de animais silvestres.

Conforme Ellis (1994), nas propriedades produtoras de leite, como as deste estudo, a alta incidência de fêmeas infectadas deve-se, em parte, ao tipo de manejo que propicia a disseminação da doença pela grande proximidade dos animais, sendo que nestes rebanhos podem existir indivíduos portadores que abrigam as leptospiras nos túbulos renais e as eliminam na urina por longos períodos de tempo, assim contaminando o meio ambiente e contribuindo para a manutenção da infecção nos rebanhos acometidos.

Na espécie bovina, as perdas econômicas causadas pela Leptospirose estão 
ligadas às falhas reprodutivas como infertilidade, abortamento, queda da produção de carne e leite, além de custos com despesas de assistência veterinária, vacinas e testes laboratoriais.

Analisando de forma geral os resultados acima apresentados, é possível observar que entre as doenças citadas neste trabalho, a que teve maior ocorrência em termos de porcentagem entre elas foi a IBR, com 57,54\% (484/842), seguida pela Leptospirose com 31,67\% (232/733) e BVD com 28,5\% (240/842), conforme Gráfico 4.

\section{INCIDÊNCIA DE DOENÇAS}

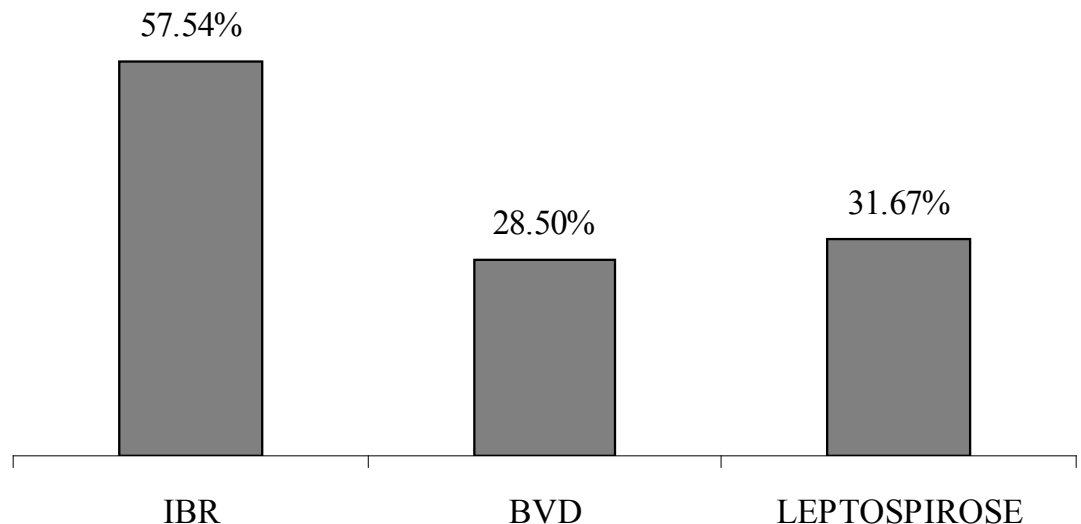

Gráfico 4. Comparativo de resultados positivos de IBR, BVD e Leptospirose em propriedades do Oeste de Santa Catarina.

Fonte: Elaborado pelos autores (2013).

Diante do exposto, os resultados desta pesquisa evidenciaram uma situação preocupante, determinada pelas altas taxas de incidência encontradas para as três doenças estudadas. Os índices apresentados neste estudo apesar de se assemelharem a outros determinados por outras pesquisas, tanto em Estados brasileiros como em outros países, justificam-se de certa maneira estes valores, por se tratarem de propriedades e animais com históricos de problemas reprodutivos, onde os quais por algum motivo não conseguiram manter seu potencial produtivo. Seguramente 
os sistemas de criação empregados na atualidade estão muito aliados às falhas de manejo sanitário e reprodutivo, os quais condicionam uma maior disseminação das infecções.

Esta alta incidência denota que existem falhas nos manejos sanitários e reprodutivos empregados em muitas propriedades, o que pode ser observado não só pela presença das doenças nos animais amostrados, mas também pela constatação nas propriedades de que os programas preventivos se instituídos, não seguem muitas vezes uma conduta técnica, orientada por um profissional competente ou idôneo. O que se observa é que estes programas são aplicados sob orientação de leigos no assunto e somente com interesses comerciais. Ou mesmo porque um vizinho iniciou a implantação de programa, e este protocolo é também aplicado na propriedade, o que na maioria das vezes não resolve os problemas presentes, o que contribui ainda mais na disseminação destas doenças, por pensarem que estas estão sendo controladas.

$\mathrm{O}$ enfoque mais globalizado da situação evidencia um quadro potencialmente crítico, onde a verificação das altas prevalências de BVD, IBR e Leptospirose representam não só a deterioração das condições de saúde da maioria dos animais testados e mais amplamente dos rebanhos, mas também a falta de um programa eficaz no controle destas doenças, a fim de minimizar os prejuízos vividos pela pecuária leiteira em nosso país.

Este manejo geral falho, por parte dos produtores e das entidades representativas, frequentemente propicia o convívio íntimo e prolongado de bovinos doentes, fontes naturais e potenciais disseminadores de agentes infecciosos, com animais sadios, continuamente expostos ao risco de infecções. Nos rebanhos onde isto ocorre, percebe-se a performance produtiva comprometida pela diminuição da produtividade leiteira e do desfrute reprodutivo do rebanho, além de um grande aumento nos custos de serviços veterinários e futuramente enfrentarão problemas com restrições comerciais aos animais e seus produtos, devido às pressões que as empresas coletoras de leite irão exercer para adquirir um produto lácteo de boa qualidade. 


\subsection{SUGESTÕES E PROPOSTAS}

Estudo de programas de saúde animal para a prevenção de doenças infectocontagiosas da reprodução animal deve ser constantemente estimulado, tendo em vista a alta disseminação destas no rebanho nacional e somente trabalhos focados na prevenção é que poderão controlar os índices de ocorrência e diminuir os prejuízos econômicos que são provocados por elas (DEL FAVA et al., 2003). Também é importante considerar que uma destas doenças, a Leptospirose, além dos prejuízos à produção traz riscos de infecção humana, o que torna prioritário seu controle, perante os índices encontrados de ocorrência nas propriedades da região.

Para controle sanitário dos rebanhos e das doenças reprodutivas anteriormente descritas, são fundamentais práticas de manejo adequadas que devem envolver:

- Controle na aquisição e introdução de novos animais na propriedade: todos os animais adquiridos devem passar por exames sorológicos para diagnósticos de doenças e período de quarentena;

- Cuidados na inseminação artificial e qualidade do sêmen utilizado;

- Realizar periodicamente exames ginecológico, andrológico e sorodiagnóstico dos animais do plantel e reprodutores;

- Eliminar do rebanho os animais que são positivos aos agentes, que não respondem aos tratamentos e atuam como fonte constante de contaminação do rebanho;

- Realizar programas de controle de roedores e animais silvestres na propriedade;

- Adoção de calendários de vacinação, que devem ser seguidos corretamente e efetuados de acordo com a orientação de um técnico.

\subsection{PLANO DE AÇÃO}

As manifestações clínicas da infecção pelo vírus BHV-1 e BHV-5, pelo BVD e pelas Leptospiras podem ser controladas e prevenidas pelo uso de programas de 
vacinação. Embora não impeça a infecção pelo agente, o uso da vacina minimiza os sintomas e reduz o curso das enfermidades.

Na sequência se apresenta um cronograma (Quadro 2) de vacinação sugerido às propriedades positivas para as doenças apresentadas ou mesmo àquelas que desejam prevenir surtos das doenças e dessa forma evitar prejuízos econômicos. Este esquema foi planejado a partir de sugestões citadas na literatura, utilizandose uma vacina comercial, composta por vírus inativado, que possui hidróxido de alumínio como adjuvante e presença de 13 antígenos, dentre estes os dois vírus causadores da IBR (BHV-1 e BHV-5), o BVD e 6 diferentes sorovares de Leptospira. Mudanças no esquema de vacinação podem ser necessárias de acordo com a incidência dos agentes em cada propriedade ou a critério do técnico responsável pelo controle sanitário.

Quadro 2. Esquema de vacinação.

\begin{tabular}{|l|c|c|c|c|c|}
\hline Doença & $\begin{array}{c}\text { Via de Admi- } \\
\text { nistração }\end{array}$ & Dose & $\mathbf{1}^{\text {a }}$ Dose & Reforço & Revacinação \\
\hline IBR & Subcutânea & $5 \mathrm{ml}$ & $\begin{array}{c}\text { Animais a partir } \\
\text { de } 4 \text { meses de } \\
\text { idade }\end{array}$ & $\begin{array}{c}21 \text { a } 30 \text { dias } \\
\text { após a } 1^{\text {a }} \text { dose }\end{array}$ & $\begin{array}{c}\text { Todo rebanho } \\
\text { anualmente }\end{array}$ \\
\hline BVD & Subcutânea & $5 \mathrm{ml}$ & $\begin{array}{c}\text { Animais a partir } \\
\text { de } 4 \text { meses de } \\
\text { idade }\end{array}$ & $\begin{array}{c}21 \text { a } 30 \text { dias } \\
\text { após a } 1^{\text {a dose }}\end{array}$ & $\begin{array}{c}\text { Todo rebanho } \\
\text { anualmente }\end{array}$ \\
\hline $\begin{array}{l}\text { Leptospi- } \\
\text { rose }\end{array}$ & Subcutânea & $5 \mathrm{ml}$ & $\begin{array}{c}\text { Animais a partir } \\
\text { de } 4 \text { meses de } \\
\text { idade }\end{array}$ & $\begin{array}{c}21 \text { a } 30 \text { dias } \\
\text { após a } 1^{\text {a dose }}\end{array}$ & $\begin{array}{c}\text { Todo o reba- } \\
\text { nho semes- } \\
\text { tralmente }\end{array}$ \\
\hline
\end{tabular}

Fonte: Adaptado de Manual Técnico de Produtos Vallée (2010).

São as medidas preventivas e mitigadoras que irão contribuir sobremaneira para mudarmos a realidade das propriedades do Oeste catarinense.

\section{CONSIDERAÇÕES FINAIS}

A baixa eficiência reprodutiva pode comprometer economicamente e de maneira decisiva a produção leiteira, podendo atingir mesmo aqueles animais que 
são submetidos a condições de manejo adequadas e condições nutricionais otimizadas. Os problemas responsáveis pela baixa eficiência podem ser de diversas fontes e muito frequentemente estão relacionados à incidência de doenças infectocontagiosas que afetam o sistema reprodutivo, em muitas situações, de maneira silenciosa e com altos índices. Dentre as doenças que comprometem a taxa reprodutiva estão a IBR, a BVD e a Leptospirose, que se encontram amplamente distribuídas no Brasil e com altas taxas de infecção. Para que o controle dos agentes causadores destas doenças seja feito de maneira eficiente, é necessário conhecer suas características, suas vias de transmissão e principalmente a sua incidência, para que as medidas adotadas sejam de acordo com a real necessidade de cada rebanho.

Poucos relatos sobre a ocorrência destas doenças infectocontagiosas na região Oeste de Santa Catarina são encontrados, porém, é de conhecimento de profissionais da área e de produtores, as constantes perdas reprodutivas em rebanhos onde são descartadas outras possíveis causas para estas perdas. A isso soma-se o fato de existir, por parte dos produtores, uma posição de não utilização de esquemas de vacinação constantes e eficientes, muitas vezes pela justificativa de não haver a necessidade de tal prática, pela baixa ocorrência destas doenças e o alto custo que envolve a adoção da vacinação.

Através deste estudo foi possível identificar uma alta incidência dos agentes causadores de IBR, BVD e Leptospirose em rebanhos que apresentam animais com problemas reprodutivos (abortos, repetição de cio, alto intervalo entre partos), pertencentes a 195 propriedades localizadas na região Oeste de Santa Catarina. Das 842 amostras coletadas, 482 foram positivas para a presença do vírus causador da IBR, 240 positivas para a BVD e 229 positivas para Leptospira. Estes números assemelham-se aos dados obtidos por outros autores em amostras coletadas nas mais diversas regiões do país.

Práticas de manejo como controle na aquisição e introdução de novos animais, cuidados na inseminação artificial, realização periódica de exames e controle de roedores e animais silvestres são de fundamental importância em todas as propriedades. Porém, considerando todas as perdas decorrentes de doenças infectocontagiosas de ordem reprodutiva, a alta ocorrência nas propriedades analisadas e a capacidade de disseminação destas, se faz estritamente necessária a adoção de 
programas de saúde animal que envolvam a utilização de calendários de vacinação contra os agentes causadores de IBR, BVD e Leptospirose, que devem ser criteriosamente seguidos, para que se possa obter melhores resultados e principalmente um eficiente controle destas doenças, pois o futuro da pecuária leiteira está amplamente ligado a estes procedimentos.

Recomenda-se para futuros estudos ampliar a amostragem para outras bacias leiteiras do Estado de Santa Catarina e do Sul do país. Desse modo, será possível estabelecer comparativos de resultados obtidos em diferentes regiões.

\section{REFERÊNCIAS}

BARR, B. C.; ANDERSON, M. L. Infectious diseases causing bovine abortion and fetal loss. Vet. Clin. North Am. Food Anim. Pract., v. 9, n. 2, p. 343-368, 1993.

CASTRO, V.; AZEVEDO, S. S.; GOTTI, T. B.; BATISTA, C. S. A.; GENTILI, J.; MORAIS, Z. M.; SOUZA, G. O.; VASCONCELLOS, S. A.; GENOVEZ, M. E. Soroprevalência da leptospirose em fêmeas bovinas em idade reprodutiva no Estado de São Paulo, Brasil. Arq. Inst. Biol, São Paulo, v. 75, n. 1, p. 3-11, 2008.

DEL FAVA, C. et al. Manejo sanitário para o controle de doenças da reprodução em um sistema leiteiro de produção semi-intensivo. Arq. Inst. Biol., São Paulo, v. 70, n. 1, p. 25-33, jan./mar., 2003.

DIAS, J. A. et al. Fatores de risco associados à infecção pelo herpesvírus bovino $1 \mathrm{em}$ rebanhos bovinos da região Oeste do Estado do Paraná. Pesq. Vet. Bras. v. 28, n. 3, p. $161-168$, mar. 2008.

ELLIS, W. A. Leptospirosis as a cause of reproductive failure. The Veterinary clinics of North America. Food animal practice v. 10, p. 463-478, 1994.

FLORES, E.F. et al. A infecção pelo vírus da Diarréia Viral Bovina (BVDV) no Brasil histórico, situação atual e perspectivas. Pesq. Vet. Bras., v. 25, n. 3, p. 125-134, jul./ set. 2005 . 
GIL, A.C. Métodos e técnicas de pesquisa social. 5. ed. São Paulo: Atlas, 2007, p. $43,65,72$.

HALFEN, D.C.; VIDOR, T. Infecções por herpesvírus bovino-1 e herpesvírus bovino-5. In: RIET-CORREA et al. Doenças de ruminantes e eqüinos. São Paulo: Livraria Varela, 2001. vol. I, 426 p.

KRAHL, M. et al. Pesquisa de anticorpos para leptospirose, rinotraqueíte infecciosa bovina e diarréia viral bovina em soros bovinos de propriedades rurais do Rio Grande do Sul. In: CONGRESSO BRASILEIRO DE MEDICINA VETERINÁRIA, 25., 1997, Gramado. Anais... Gramado: Sociedade Brasileira de Medicina Veterinária, 1997. p. 174 .

LEMAIRE, M.; PASTORET, P.P.; THIRY, E. Le contrôle de l'infection pas le virus de la rhinotrachéite infectieuse bovine. Ann. Méd. Vét., v. 138, n. 3, p. 167-180, 1994.

MANUAL TÉCNICO DE PRODUTOS VALLÉE. Poliguard e Fertiguard. Uberlândia, MG: Vallée, 2010. 27p.

MENDES, M.B. et al. Determinação da prevalência das principais doenças da reprodução no rebanho bovino da região de Uberaba-MG. Ciência Animal Brasileira, p. 772 - 777 , out. 2009.

MINISTÉRIO DA SAÚDE. Fundação Nacional de Saúde. Manual de leptospirose. Brasília, 1995. p.97.

OIE. ORGANIZAÇÃO INTERNACIONAL DE EPIZOOTIAS. World Organisation for Animal Health. Leptospirosis, Chapter 2.2.4. 2006. Disponível em: < http://www.oie. int/eng/normes/mmanual/A_00043.htm > . Acesso em: 14 maio 2013.

PEREIRA, H. M. et al. Frequência de anticorpos contra o vírus da Diarréia Viral Bovina (BVDV) em bovinos leiteiros não vacinados na bacia leiteira da Ilha de São Luíz-MA. Ciência Animal Brasileira, p. 496-501, out. 2009. Disponível em: < http://www.revistas.ufg.br/index.php/vet/article/viewArticle/7847/5651>. Acesso em: 05 fev. 2013. 
PIVETTA, C.G. Efeitos da leptospirose sobre a reprodução e a produção em rebanhos leiteiros e estimativa da herdabilidade. 1999. 58F. Dissertação (Programa de Pós Graduação em Zootecnia) - Universidade Federal de Santa Maria, Santa Maria, 1999.

RICHTZENHAIN, L. J.; B ARBARINI, O.; U MEHARA, O.; DE GRAÇA, A. S.; CORTEZ, A.; HEINEMANN, M. B.; FERREIRA, F.; SOARES, R. M. Diarreia viral bovina: levantamento sorológico nos estados de Minas Gerais, Mato Grosso do Sul, São Paulo, Rio de Janeiro, Paraná e Rio Grande do Sul. Arq. Inst. Biol., São Paulo, v.66, n.1. p.107-111, 1999.

SCHUCH, L. F. D. Diarréia viral bovina. In: RIET-CORREA et al. Doenças de ruminantes e eqüinos. São Paulo: Varela, 2001. Vol. I, 426 p.

VIDOR, T. et al. Herpes bovino tipo 1 (BHV-1): I. Sorologia de rebanhos com problemas reprodutivos. Ciência Rural, v. 25, n. 3, p. 421-424, 1995.

Recebido em: 28 de agosto de 2013. Aceito em: 14 de maio de 2014 